\title{
Bone mineral density and nutritional status in children with chronic inflammatory bowel disease
}

\author{
A M Boot, J Bouquet, E P Krenning, S M P F de Muinck Keizer-Schrama
}

\begin{abstract}
Background-Osteoporosis has been reported in adult patients with inflammatory bowel disease.

Aims-To evaluate bone mineral density (BMD), nutritional status, and determinants of BMD in children with inflammatory bowel disease.

Patients-Fifty five patients ( 34 boys and 21 girls, age range 4-18) were studied; 22 had Crohn's disease and 33 ulcerative colitis.

Methods-Lumbar spine and total body BMD, and body composition were assessed by dual energy $x$ ray absorptiometry (DXA). Results were expressed as standard deviation scores (SDS). Lean body mass was also assessed by bioelectrical impedance analysis (BIA). Yearly measurements during two years were performed in 21 patients.
\end{abstract}

Results-The mean SDS of lumbar spine BMD and total body BMD were significantly lower than normal $(-0.75$ and -0.95 , both $p<0.001)$. Height SDS and body mass index SDS were also decreased. The decrease in BMD SDS could not be explained by delay in bone maturation. The cumulative dose of prednisolone correlated negatively with lumbar spine BMD SDS $(r=-0.32, p<0.02)$. Body mass index SDS correlated positively with total body BMD SDS $(r=0.36, p<0.02)$. Patients with Crohn's disease had significantly lower lumbar spine and total body BMD SDS than patients with ulcerative colitis, even after adjustment for cumulative dose of prednisolone. In the longitudinal data cumulative dose of prednisolone between the measurements correlated negatively with the change in lumbar spine and total body BMD SDS. Lean tissue mass measured by DXA had a strong correlation with lean body mass measured by BIA $(r=0.98)$.

Conclusions-Children with inflammatory bowel disease have a decreased BMD. Children with Crohn's disease have a higher risk of developing osteopaenia than children with ulcerative colitis. Corticosteroid therapy and nutritional status are important determinants of BMD in these patients.

(Gut 1998;42:188-194)

Keywords: bone mineral density; inflammatory bowel disease; children; nutritional status; corticosteroid treatment; body composition
Several studies have reported an increased prevalence of osteoporosis in adult patients with chronic inflammatory bowel disease (IBD).${ }^{1-4}$ An increased rate of spinal bone loss was found in $54 \%$ of adult patients with IBD. ${ }^{5}$

Retardation of growth and skeletal maturation are common in children with IBD. ${ }^{67} \mathrm{~A}$ study of children with Crohn's disease reported decreased bone mass of the distal radius, measured with single photon absorptiometry. ${ }^{8}$ Two other studies reported low bone mineral density (BMD) in children with IBD. ${ }^{910}$ Children with osteopaenia have a higher risk of fractures in childhood and also in adulthood because of not reaching their optimal peak bone mass.

In recent years it has been possible to measure BMD quantitatively by dual energy $x$ ray absorptiometry (DXA), which, due to its short scan time and low radiation dose, is suitable for use in children. ${ }^{11}$ With the total body measurement, body composition in lean tissue mass, fat mass, and bone mineral content are assessed.

In the present study, using cross sectional and longitudinal data, we investigated the prevalence of and risk factors for a low BMD in children and adolescents with Crohn's disease or ulcerative colitis. The results of body composition measurements by DXA were compared with those obtained by bioelectrical impedance analysis.

\section{Patients and methods}

PATIENTS

Fifty five patients ( 34 boys and 21 girls) with chronic inflammatory disease were studied. Twenty two patients had Crohn's disease and 33 had ulcerative colitis. Diagnosis was made according to the Dutch children's IBD consensus guidelines. ${ }^{12}$ The mean age was 13 years (range 4-18 years). Thirty six patients were studied prospectively. The intervals between DXA measurements were about one year. Thirty six patients were followed for a period of one year, and 21 for a period of two years. Fourteen patients had Crohn's disease of the small bowel, four of the colon, and four of both. Five patients underwent an ileocaecal resection before the first measurement. Two patients with ulcerative colitis also had sclerosing pericholangitis and one also had ulcerative colitis from chronic active hepatitis. The duration of the symptoms of the disease ranged from one month to 12 years (median duration 2.2 years).

The total lifetime cumulative dose of prednisolone (in $\mathrm{mg}$ ) was calculated at the first measurement and also the cumulative dose 
between the yearly measurements. Twenty patients $(36 \%)$ had not been treated with corticosteroids before the first measurement. Three of these received corticosteroids before the second measurement. All patients had been treated with sulphasalazine or mesalazine.

METHODS

Height was measured with a Harpenden stadiometer. Height was compared to age and sex matched reference values ${ }^{13}$ and expressed as standard deviation scores (SDS). Weight was assessed by a standard clinical balance. The body mass index was calculated as weight/ height ${ }^{2}\left(\mathrm{~kg} / \mathrm{m}^{2}\right)$, compared to age and sex matched reference values, ${ }^{14}$ and expressed as SDS.

Pubertal development was determined according to Tanner. ${ }^{15}$ For patients in puberty, delay in puberty was calculated by comparison of Tanner stage and age of the patients with reference data of Dutch children. ${ }^{13}$ The delay was calculated as the difference between the age of the patient and the median age of the next Tanner stage of the reference group.

BMD of the lumbar spine and total body was measured by DXA (Lunar, DPXL/PED, Lunar Radiation Corporation, Madison, Wisconson, USA). The coefficient of variation has been reported as $1.04 \%$ for lumbar spine and $0.64 \%$ for total body. ${ }^{16}$ The coefficient of variation was $1.1 \%$ (SD 0.2) in our setting. BMD results were compared to our age and sex matched Dutch reference values $(n=500)^{17}$ and expressed as SDS. Patients with a BMD SDS below -1.5 were given supplements of calcium $500 \mathrm{mg}$ per day and vitamin D 400 units per day.

With the total body measurement by DXA the body composition was measured as lean tissue mass, fat mass, and bone mineral content. Total tissue mass is the sum of these three variables. Percentage body fat is given for total tissue mass. The coefficients of variation have been reported as $2.2 \%$ for fat mass, $1.1 \%$ for lean tissue mass, and $0.6 \%$ for bone mineral content. ${ }^{16}$ Bone mineral content, lean tissue mass, fat mass, and percentage body fat were compared to our age and sex matched Dutch reference values and expressed as SDS. ${ }^{18}$

Lean body mass was also estimated with bioelectrical impedance analysis (BIA 101, RJL Systems, Detroit, Michigan). Two skin electrodes were placed on the dorsal surface of the left hand and wrist, and two electrodes on the surface of the left foot and ankle joint, according to the standard procedure as described previously. ${ }^{19}$ Whole body resistance and reactance were measured. With these values and also age, sex, weight, and height, the lean body mass was calculated by a programme provided by the manufacturer with separate programmes for children (4-12 years), adolescents (13-16 years), and adults (17 years and older). A total of 103 measurements with BIA were compared to simultaneous DXA measurements. No oedema was present in any of the patients.

Dietary calcium intake and total caloric intake were assessed in 36 patients by a dietitian using a three day food intake diary. The results were compared to the recommended Dutch intake of calcium and calories with respect to sex and age group.

During an interview children above 10 years of age were asked about their daily habitual physical activity, ${ }^{20}$ which included physical education classes, organised sports, recreational activity, and habitual walking and cycling. The results were compared to the healthy controls of the BMD reference population in which the same questionnaire was used. ${ }^{17}$

Bone age was assessed in 52 children by one investigator (AB) using an $x$ ray of the left hand according to the Tanner-Whitehouse radiusulna-short bones (RUS method). ${ }^{21}$ Two $x$ rays of the hand were taken in 30 patients and three $x$ rays in 14 patients with intervals of about one year.

Blood samples were taken at the first measurement for the assessment of calcium, phosphate, alkaline phosphatase, parathyroid hormone, 25-hydroxyvitamin D, 1,25dihydroxyvitamin $\mathrm{D}$, osteocalcin, the carboxy terminal propeptide of type I collagen (PICP), and insulin like growth factor I (IGF-I). Serum intact parathyroid hormone was determined in 21 patients by radioimmunoassay (Nichols Institute, San Juan Capistrano, California, USA). 25-Hydroxyvitamin D was assessed in 42 patients and 1,25-dihydroxyvitamin $\mathrm{D}$ in 23 patients. The following were measured by radioimmunoassay: osteocalcin and 25hydroxyvitamin D (Incstar Corporation, Stillwater, USA), 1,25-dihydroxyvitamin D (Immuno Diagnostic Systems, Boldon, UK), and PICP (Orion Diagnostica, Espoo, Finland). Osteocalcin was assessed in 41 patients and PICP in 39 patients. Our own reference values for osteocalcin and PICP $(n=25$ and $n=82$ respectively) were used for prepubertal children. Reference values for the older children were taken from other studies which used the same assay methods. ${ }^{22-24}$ For measurements of IGF-I, kits from Med-Genix Diagnostics, Fleurus, Belgium, were used. IGF-I was assessed in 50 patients. IGF-I sex and age matched reference values were based on 600 samples of a healthy Dutch population. ${ }^{25}$ The ratio of hydroxyproline and creatinine was evaluated in 24 hour urine in 47 patients and compared to reference values. ${ }^{26}$

\section{STATISTICS}

One sample $t$ tests were performed to compare the mean SDS values to normal values. Two sample $t$ tests were used to compare variables with a normal distribution between two groups. The Pearson correlation coefficient was calculated to test the association between two variables with a normal distribution. Spearman's rank correlation coefficient was utilised in case of a non-normal distribution. Multiple regression analysis was used for adjustment of confounders and to test possible pathogenic factors of osteopaenia simultaneously. One way analysis of variance was performed to test differences in more than two groups. 

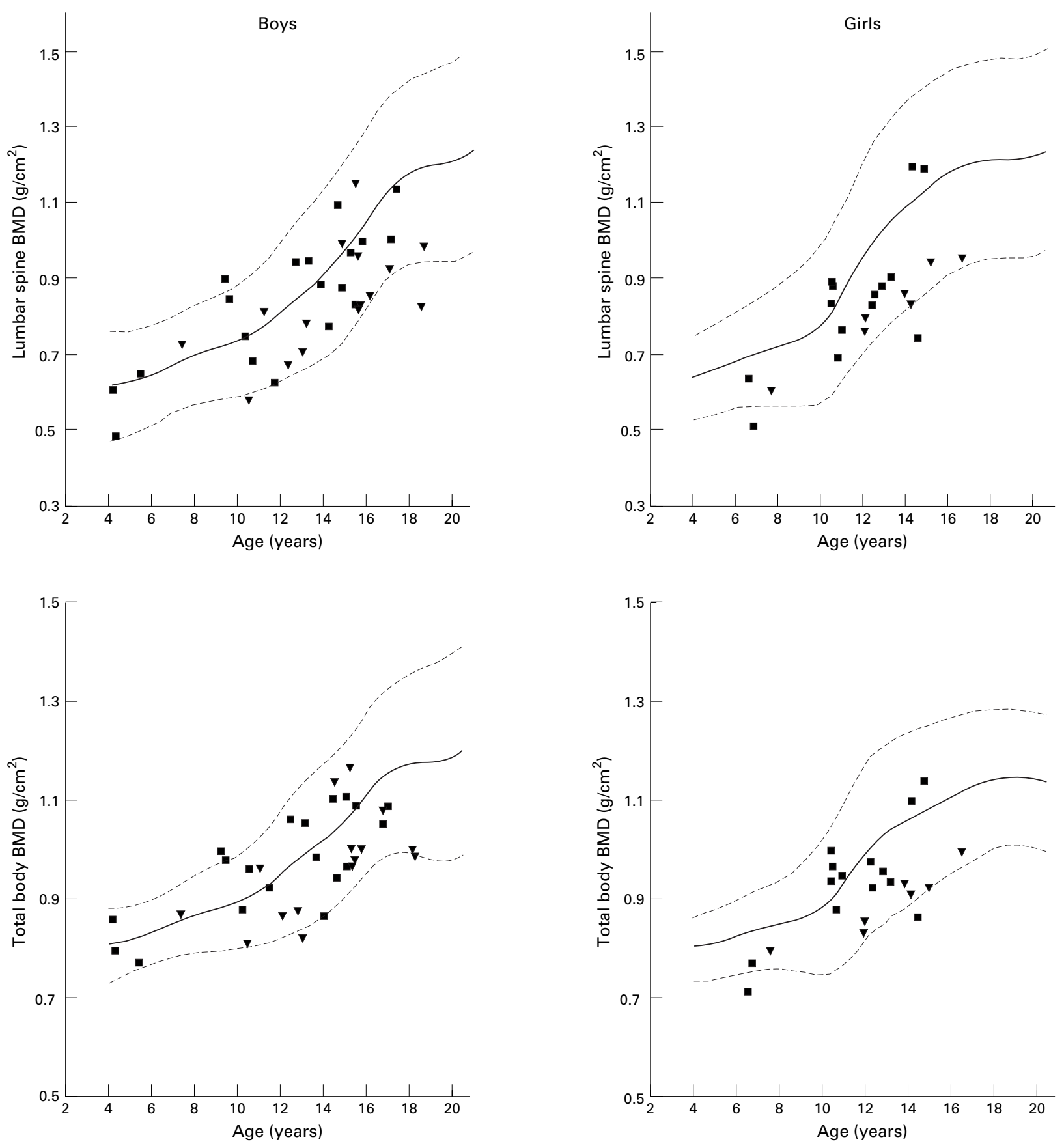

$\checkmark$ Crohn's disease

- Ulcerative colitis

Figure 1 Lumbar spine and total body BMD results of the first measurement in 55 patients with IBD. The continuous line represents the mean of reference values, the dotted lines +2 and $-2 S D$.

\section{Results}

Mean SDS of the lumbar spine BMD at the first measurement was -0.75 (SD 1.20), and of total body BMD -0.95 (1.22); both values were significantly lower than reference values $(\mathrm{p}<0.001)$. Four patients $(7 \%)$, of whom one had not been treated with corticosteroids, had lumbar spine BMD SDS below -2 and eight patients $(15 \%)$, of whom three had not used corticosteroids before, had total body BMD SDS below -2 . Figure 1 shows the BMD results. Mean BMD SDS of boys was not significantly different from that of girls. None of the patients experienced a fracture during the study period.

The mean delay in bone maturation (chronological age minus bone age) was 0.71 years (SD 1.63). If the BMD SDS was calculated for bone age instead of chronological age, the mean lumbar spine BMD SDS was -0.47 (1.04) and total body BMD SDS -0.80 (1.04), both still significantly below zero $(\mathrm{p}<0.01$ and $\mathrm{p}<0.001$ respectively). The delay in bone maturation had a significant negative correlation with lumbar spine BMD SDS $(r=-0.47, \mathrm{p}<0.001)$ and total body BMD SDS 
Table 1 Correlation coefficients of various variables with lumbar spine and total BMD SDS in all 55 children with inflammatory bowel disease, and separately in the patients with Crohn's disease $(C D ; n=22)$ and ulcerative colitis (UC; $n=33$ )

\begin{tabular}{|c|c|c|c|c|c|c|}
\hline & \multicolumn{3}{|c|}{ Lumbar spine BMD SDS } & \multicolumn{3}{|c|}{ Total body BMD SDS } \\
\hline & All & $C D$ & $U C$ & All & $C D$ & $U C$ \\
\hline Height SDS & $0.54^{\star \star \star}$ & 0.18 & $0.59^{\star \star \star}$ & $0.59^{\star \star \star}$ & 0.39 & $0.56^{\star \star \star}$ \\
\hline BMI SDS & 0.19 & 0.11 & 0.05 & $0.35^{\star \star}$ & $0.47^{\star}$ & 0.14 \\
\hline \multicolumn{7}{|l|}{ Cumulative dose of } \\
\hline prednisolone (mg) & $-0.32^{\star \star}$ & -0.40 & $-0.35^{\star}$ & -0.19 & -0.26 & -0.22 \\
\hline Lean tissue mass SDS & $0.56^{\star \star \star}$ & 0.35 & $0.58^{\star \star \star}$ & $0.61^{\star \star \star}$ & $0.58^{\star \star}$ & $0.52^{\star \star}$ \\
\hline Fat mass SDS & 0.08 & -0.14 & 0.04 & $0.31^{\star}$ & 0.10 & 0.29 \\
\hline
\end{tabular}

${ }^{\star} \mathrm{p}<0.05,{ }^{\star \star} \mathrm{p}<0.01,{ }^{\star \star \star} \mathrm{p}<0.001$.

$\mathrm{BMI}$, body mass index.

$(r=-0.45, \mathrm{p}<0.001)$. The mean delay of puberty was 0.70 years (1.14). A greater delay related to lower lumbar spine BMD SDS $(r=-0.45, \mathrm{p}<0.01)$ and total body BMD SDS $(r=-0.54, \mathrm{p}<0.001)$.

The mean height SDS was -0.54 (SD 1.25) and body mass index SDS -0.66 (0.85), both significantly below zero $(\mathrm{p}<0.01$ and $\mathrm{p}<0.001$ respectively). Table 1 lists correlations of various variables with BMD SDS. The correlation coefficients are similar for Crohn's disease and ulcerative colitis.

The total lifetime cumulative dose of prednisolone until the first measurement (median dose $1.68 \mathrm{~g}$, range $0-35$ ) had a significant negative association with lumbar spine BMD SDS but not with total body BMD SDS.

The children with Crohn's disease had significantly lower lumbar spine and total body BMD SDS and height SDS than children with ulcerative colitis $(p=0.01$ for lumbar spine and $p=0.003$ for total body and height), even after adjustment for cumulative dose of prednisolone.

The mean physical activity was 8.3 hours per week (SD 4.6) for boys and 5.9 hours per week (3.1) for girls, both not significantly different from controls (9.2 and 7.1 hours per week respectively). We found no correlation between physical activity and lumbar spine or total body BMD SDS.

Lumbar spine or total body BMD SDS did not differ between patients who had had a previous ileocaecal resection and patients who had had no resection.

The duration of the disease did not relate to lumbar spine or total body BMD SDS.

In multiple regression analysis with diagnosis (Crohn's disease/ulcerative colitis), cumulative dose of prednisolone and body mass index SDS as determinants and BMD SDS as dependent variable, cumulative dose of prednisolone and diagnosis related significantly to lumbar spine BMD SDS and explained $20 \%$ of the variance. Only diagnosis related significantly to total body BMD SDS in this regression model $\left(r^{2}=15 \%\right)$.

BODY COMPOSITION AND CALORIC AND CALCIUM INTAKE

The mean SDS of lean tissue mass was -1.04 (SD 1.41), of bone mineral content -1.05 (1.27), of fat mass -0.64 (1.02), and of percentage body fat -0.38 (1.11); all were significantly lower than normal (all $\mathrm{p}<0.001$, except for percentage body fat $\mathrm{p}<0.02)$. Table
1 shows correlations of these variables with BMD SDS. The SDS of percentage body fat had no significant correlation with BMD SDS. Cumulative dose of prednisolone did not relate to lean body mass SDS or fat mass SDS. Patients with Crohn's disease had significantly lower lean body mass SDS $(p=0.003)$ than patients with ulcerative colitis. They did not differ in fat mass or percentage fat SDS.

The percentage caloric intake of the recommended daily allowance of the 36 children, whose food intake was analysed, varied from $49 \%$ to $130 \%$ (mean $92 \%$ ). Seventeen children $(47 \%)$ had a caloric intake more than $10 \%$ below the recommended daily allowance. Five children (14\%) had a low calcium intake.

BIOCHEMICAL PARAMETERS OF BONE METABOLISM Five children had decreased 25-hydroxyvitamin $\mathrm{D}$ levels and one child a low 1,25dihydroxyvitamin D level. The 25hydroxyvitamin D and 1,25-dihydroxyvitamin $D$ levels did not differ between patients with Crohn's disease and patients with ulcerative colitis. Osteocalcin was decreased in $3 / 40$ patients $(8 \%)$ and IGF-I in $11 / 50$ patients $(22 \%)$. All patients had normal PICP values. The patients with a low osteocalcin or a low IGF-I did not differ significantly in lumbar spine or total body BMD SDS, height SDS, and body mass index SDS from the other patients. The hydroxyproline:creatinine ratio was low in 18/47 children (38\%), normal in 26 $(55 \%)$, and high in three $(6 \%)$. There was a significant difference in lumbar spine and total body BMD SDS between the patients with a low, normal, and high hydroxyproline:creatinine ratio (both $\mathrm{p}<0.05$ ). If the ratio was higher the BMD SDS was lower. The other biochemical results were within normal limits.

\section{LONGITUDINAL DATA}

There was no significant change in BMD SDS between measurements 1 and $2\left(\Delta \mathrm{SDS}^{1}\right)$. The mean $\triangle \mathrm{SDS}^{1}$ of lumbar spine BMD between the first two measurements was -0.07 (SD 0.48 ) and of total body BMD 0.06 (SD 0.51). The $\Delta \mathrm{SDS}^{1}$ of lumbar spine and total body BMD was not significantly correlated with the cumulative dose of prednisolone between the measurements (median dose $0.56 \mathrm{~g}$, range $0-5.9 \mathrm{~g}$ ). Eleven of the 36 patients had received calcium and vitamin $\mathrm{D}$ treatment.

Between measurements 2 and 3 there was a significant increase in BMD $\operatorname{SDS}\left(\Delta \mathrm{SDS}^{2}\right)$. The mean $\Delta \mathrm{SDS}^{2}$ of lumbar spine $\mathrm{BMD}$ was 

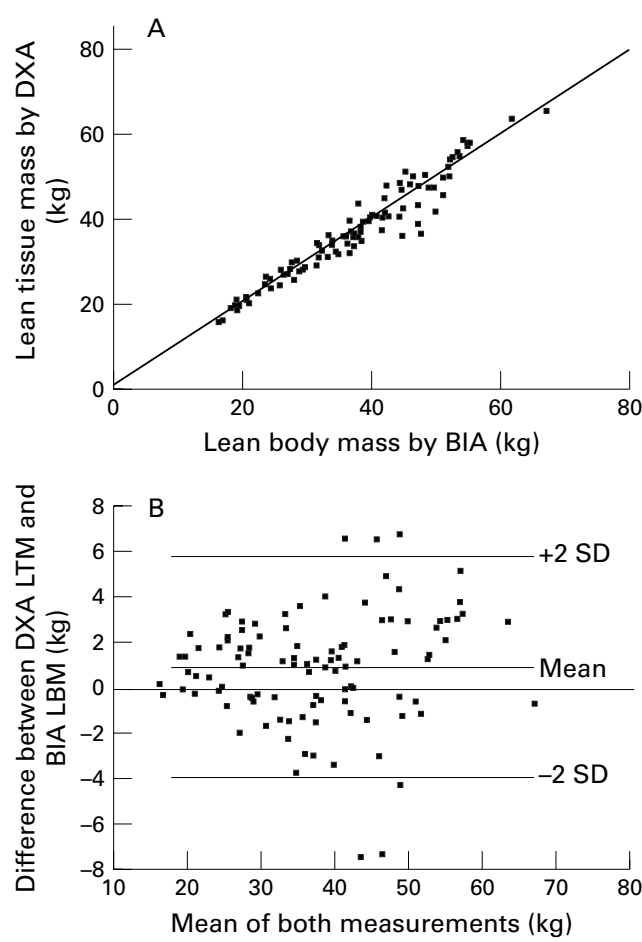

Figure 2 (A) Relation between lean tissue mass measured by DXA and lean body mass measured by BIA. The continuous line represents the regression line. (B) Difference between lean tissue mass by DXA and lean body mass by $B I A$ against the mean for the two methods. LBM, lean body mass; LTM, lean tissue mass.

0.46 (SD 0.73), and of total body BMD 0.61 (SD 0.48), both significantly higher than zero $(\mathrm{p}<0.02$ for lumbar spine and $\mathrm{p}<0.001$ for total body). The $\Delta \mathrm{SDS}^{2}$ of lumbar spine and total body BMD had a significant negative correlation with the cumulative dose of prednisolone between measurements 2 and 3 ( $r=-0.60$ for lumbar spine and $r=-0.56$ for total body, both $\mathrm{p}<0.01$ ). Median cumulative dose between the measurements was $0.34 \mathrm{~g}$ (range $0-4.6 \mathrm{~g}$ ). Six of the 21 patients had received calcium and vitamin $\mathrm{D}$ treatment.

There was no significant change in SDS of the different body composition compartments, height SDS, body mass index SDS, and delay in bone maturation between measurements 1 and 2 and between measurements 2 and 3 .

COMPARISON BETWEEN DXA AND BIA

There was a high correlation between lean tissue mass measured by DXA and lean body mass measured by BIA ( $r=0.98$ ) (fig $2 \mathrm{~A}$ ). The mean difference between DXA lean tissue mass and BIA lean body mass was $0.94 \mathrm{~kg}$. The limits of agreements ( -2 to $+2 \mathrm{SD}$ of the difference) were -4.0 to $5.9 \mathrm{~kg}$ (fig $2 \mathrm{~B}$ ). If DXA lean body mass was calculated as lean tissue mass plus bone mass, the mean difference with BIA lean body mass was higher (2.8 $\mathrm{kg}$, limits of agreement -3.9 to $8.0 \mathrm{~kg}$ ).

\section{Discussion}

Bone mineralisation was reduced in children and adolescents with IBD. BMD of lumbar spine as well as of total body were significantly lower than reference values. Both trabecular bone, present mainly in lumbar spine, and cortical bone, $80 \%$ of the total skeleton, ${ }^{27}$ were affected.

Putative pathogenic factors of osteopenia have been reported as inflammatory activity, ${ }^{28}$ steroid therapy, ${ }^{1}$ malnutrition, ${ }^{1}$ malabsorption, ${ }^{29}$ reduced calcium intake, and vitamin $\mathrm{D}$ deficiency. ${ }^{30}$

Children with Crohn's disease had lower values of lumbar spine and total body BMD than children with ulcerative colitis. This is in agreement with Compston et al ${ }^{1}$ who reported that $41 \%$ of adult patients with Crohn's disease had decreased bone mass in contrast to only $14 \%$ of patients with ulcerative colitis. Other studies reported low BMD in patients with Crohn's disease but not in patients with ulcerative colitis. ${ }^{42}$ Osteopaenia and growth failure in children have been reported to be more severe in children with Crohn's disease than in children with ulcerative colitis. ${ }^{9} 103132$ In general, small intestinal involvement and malabsorption are likely to contribute to the higher prevalence of osteoporosis in Crohn's disease when localised in the small intestine, compared to ulcerative colitis. The mechanism of osteopaenia caused by the inflammatory process is unclear. Various cytokine abnormalities have been described in Crohn's disease, ${ }^{33}$ which may stimulate bone resorption. ${ }^{34}{ }^{35}$ Our results showed a negative relation between the bone resorption marker hydroxyproline and $\mathrm{BMD}$, and no relation between bone formation markers and BMD. An increase in bone resorption might account for a decrease in $\mathrm{BMD}$ in these patients. Biphosphonates inhibit bone resorption. ${ }^{36}$ Therefore, biphosphonates might be appropriate therapy to reduce bone loss. However, there is only limited experience of the use of biphosphonates in children and adolescents. ${ }^{37}$ Band-like metaphyseal sclerosis and concentric epiphyseal and apophyseal sclerosis have been described in children treated with biphosphonates. ${ }^{38}$

Steroid therapy had a significant negative correlation with lumbar spine BMD and in the longitudinal data with the change in BMD of lumbar spine as well as of total body. Some studies reported a relation between corticosteroid use and BMD in patients with chronic inflammatory bowel disease ${ }^{1} 103940$ and others did not. ${ }^{5}$ Corticosteroids are known to have a negative influence on BMD, especially of trabecular bone. ${ }^{41}$ Corticosteroids inhibit the inflammatory process in the intestine. Since the inflammatory process itself and malabsorption as a consequence of the inflammation may also negatively influence BMD, the effect of corticosteroids on BMD is complex in patients with IBD. Furthermore, corticosteroids are used more often in patients with small bowel disease and in more severe types of inflammation.

IBD is characterised by a pattern of exacerbations of disease activity of variable severity interspersed with remissions. The variability of the disease might be the reason that we did not find a relation between the duration of the disease and BMD. 
Body mass index, lean tissue mass, and fat mass were decreased which may be related to the fact that a high proportion of the patients had an insufficient caloric intake. A low caloric intake has been reported before in patients with IBD. ${ }^{32} 4243$ Twenty two per cent of the children of the present study had a low IGF-I, which may be caused by undernutrition. ${ }^{44}$ The findings are in agreement with findings of Kirschner and Sutton ${ }^{42}$ and Thomas et $a l,{ }^{43}$ who reported low serum IGF-I levels in children with IBD. They showed an increase in IGF-I following an increase of energy intake. A higher body mass index, a parameter of the nutritional status, was related to a higher BMD, which is also found in adults. ${ }^{15}$ Nutritional recommendations have been shown to reverse growth impairment ${ }^{32} 424$ and will be beneficial for bone mineralisation. Lean tissue mass SDS correlated positively with lumbar spine and total body BMD SDS. Increased lean tissue mass, and thereby muscle mass, may be related to more physical activity which may increase BMD.

Vitamin D deficiency may play a role in the pathogenic process of bone loss. Subnormal serum 25-hydroxyvitamin $\mathrm{D}$ levels have been reported in patients with chronic IBD. ${ }^{30}{ }^{45}$ Ten per cent of the patients of the present study had decreased vitamin D levels. In a study of 150 adult patients with IBD no association was found between low BMD and low serum levels of 25-hydroxyvitamin $\mathrm{D}$ or elevated parathyroid hormone levels. ${ }^{30}$ However, vitamin D might be of benefit in the treatment of osteopaenia in these patients especially during corticosteroid therapy. Sambrook et $a l^{46}$ showed that treatment with calcium and calcitriol could prevent corticosteroid induced bone loss of the lumbar spine. In the present study a selected group was treated with calcium and vitamin $\mathrm{D}$ and may have benefited from this treatment. Placebo controlled studies in children with IBD are needed to evaluate the effect of treatment with calcium and vitamin $\mathrm{D}$ on BMD in these patients.

Delay in skeletal maturation and puberty had a significant negative correlation with BMD. However, the decrease in BMD could not be explained by the retardation in bone maturation. BMD SDS calculated for bone age was also reduced. The delay in BMD might catch up at a later age. The improvement in BMD may not be complete as shown in a study of BMD of men with late puberty. ${ }^{47}$ Adult men who had late puberty had a lower BMD than men who had a normal timing of puberty.

The correlation between lean tissue mass measured by DXA and lean body mass measured by BIA was high. However, the limits of agreement $(-4.0$ to $5.9 \mathrm{~kg}$ ) were wider than those found in healthy children $(-2.0$ to $3.9 \mathrm{~kg}){ }^{18}$ The difference between BIA lean body mass and DXA lean tissue mass was smaller than the difference between BIA lean body mass and DXA lean body mass, which includes bone mass. If BIA fat mass is calculated as weight minus BIA lean body mass, BIA fat mass is overestimated if DXA is taken as the standard. In previous studies,
DXA was shown to be an accurate method of measuring soft tissue composition by cross calibration with chemical analysis after postmortem homogenisation. ${ }^{48}{ }^{49}$ However, the advantage of BIA is that it is cheap, quick, and uses portable equipment.

From this study, it can be concluded that the mean bone mineral density of children with IBD was lower than reference values. Osteopaenia appears to be more common in children with Crohn's disease than in children with ulcerative colitis. Corticosteroid therapy and nutritional status are determinants of BMD in these patients. Long term longitudinal studies are needed to investigate whether these children will attain a normal peak bone mass, and they may benefit from calcium and vitamin D supplementation or other therapies.

The authors thank Novo Nordisk Farma BV for financial support, Rosana Topcic for her assistance in data collection, and Jopie Hensen of the Department of Nuclear Medicine for her assistance in DXA measurements.

1 Compston JE, Judd D, Crawley EO, et al. Osteoporosis in patients with inflammatory bowel disease. Gut 1987;28:410-5.

2 Genant HK, Mall JC, Wagonfeld JB, Horst JV, Lanzi LH. Skeletal demineralization and growth retardation in inflammatory bowel disease. Invest Radiol 1976;6:541-9.

3 Pigot F, Roux C, Chaussade S, et al. Low bone mineral density in patients with inflammatory bowel disease. Dig Dis Sci 1992;37:1396-403.

4 Jahsen J, Falch JA, Aadland E, Mowinckel P. Bone mineral density is reduced in patients with Crohn's disease but not in patients with ulcerative colitis: a population based study. Gut 1997;40:313-9.

5 Motley RJ, Crawley EO, Evans C, Rhodes J, Compston JE. Increased rate of spinal trabecular bone loss in patient with inflammatory bowel disease. Gut 1988;29:1332-6.

6 Kirschner BS, Voinchet O, Rosenberg IH. Growth retardation in inflammatory bowel disease. Gastroenterology 1978; 75:504-11.

7 Griffith AM, Nguyen P, Smith C, MacMillan JH, Sherman PM. Growth and clinical course of children with Crohn's disease. Gut 1993;34:939-43.

8 Issenman RM, Atkinson SA, Radoja C, Fraher L. Longitudinal assessment of growth, mineral metabolism, and bone mass in pediatric Crohn's disease. 7 Pediatr Gastroenterol Nutr 1993;17:401-6.

9 Cowan FJ, Warner JT, Dunstan FDJ, Evans WD, Gregory JW, Jenkins HR. Inflammatory bowel disease and predisposition to osteopenia. Arch Dis Child 1997;76:325-9.

10 Gokhale R, Favus M, Karrison T, Rich B, Sutton M, Kirschner BS. Bone mineral density assessment in pediat-
ric patients with inflammatory bowel disease [abstract]. ric patients with inflammatory
Gastroenterology 1995;108:A825.

11 Mazess RB, Barden HS, Bisek JP, Hanson J. Dual-energy absorptiometry for total body and regional bone mineral and soft tissue composition. Am f Clin Nutr 1990;51: $1106-12$.

12 Büller HA, Maas SM. Consensus inflammatory bowel disease in children: ulcerative colitis and Crohn's disease. Ned Tijdschr Geneeskd 1996;140:544-50.

13 Roede MJ, Van Wieringen JC. Growth diagrams 1980, The Netherlands. Third nation wide survey. T Soc Gezondheidszorg 1985;63(suppl): 1-34.

14 Weststrate JA, Deurenberg $\mathrm{P}$, Tinteren $\mathrm{H}$ van. Body fat distribution and adiposity indices in Dutch children 0-18 years of age. Int f Obes 1989;13:465-77.

15 Tanner JM, Whitehouse RH. Longitudinal standards for height, weight-height, weight-velocity and stages of puheight, weight-height, weight-velocity

16 Johnson J, Dawson Hughes B. Precision and stability of dual-energy x-ray absorptiometry measurements. Calcif Tissue Int 1991;49:174-8.

17 Boot AM, de Ridder MAJ, Pols HAP, Krenning EP, de Muinck Keizer-Schrama SMPF. Bone mineral density in children and adolescents; relation to puberty, calcium intake and physical activity. If Clin Endocrinol Metab 1997;82:57-62.

18 Boot AM, Bouquet J, de Ridder MAJ, Krenning EP, de Muinck Keizer-Schrama SMPF. Determinants of body composition, measured by dual energy-x-ray absorptiometry, in Dutch children and adolescents. Am $\mathcal{f}$ Clin Nutr 1997;66:232-8

19 Lukaski HC, Johnson PE, Bolonchuk WW, Lykken GI. Assessment of fat-free mass using bioelectrical impedance measurements of the human body. Am f Clin Nutr 1985;41:810-7.

20 Verschuur R, Kemper HCG. Habitual physical activity. Med Sport Sci 1985;20:56-65. 
21 Tanner JM, Whitehouse RH, Cameron N, Marshall WA, Healy MJR, Goldstein H. Assessment of skeletal maturity and
prediction of adult height (TW2 method). 2nd edn. London: prediction of adult height

22 Kruse K, Kracht U. Evaluation of serum osteocalcin as an index of altered bone metabolism. Eur $\mathcal{F}$ Pediatr 1986;145: $27-33$

23 Bluhmsohn A, Hannon RA, Wrate R, et al. Biochemical markers of bone turnover in girls during puberty. Clin Endocrinol 1994;40:663-70.

24 Hertel NT, Stoltenberg M, Juul A, et al. Serum concentrations of type I and III procollagen propeptides in healthy children and girls with central precocious puberty during treatment with gonadotropin-releasing hormone analog and cyproterone acetate. F Clin Endocrinol Metab 1993;76: 924-7.

25 Hokken-Koelega ACS, Hackeng WHL, Stijnen T, Wit JM, de Muinck Keizer SMPF, Drop SLS. Twenty-four hour plasma growth hormone profiles, urinary GH excretion and plasma insulin-like growth factor-I and -II levels in prepubertal children with chronic renal insufficiency and severe growth retardation. $\mathcal{F}$ Clin Endocrinol Metab 1990;71: 688-95.

26 Tietz NW. Clinical guide to laboratory tests. 3rd edn. Philadelphia: Saunders, 1995.

27 Martin TJ, Ng KW, Nicholson GC. Cell biology of bone. Baillieres Clin Endocrinol Metab 1988;2:1.

28 Scharla SH, Minne HW, Lempert UG, et al. Bone minera density and calcium regulating hormones in patients with inflammatory bowel disease (Crohn's disease and ulcerative colitis). Exp Clin Endocrinol 1994;102:44-9.

29 Ghosh S, Cowen S, Hannan WJ, Feguson A. Low bone mineral density in Crohn's disease, but not in ulcerative colitis. Gastroenterology 1994;107:1031-9.

30 Silvennoimen J. Relationships between vitamin D, parathyroid hormone and bone mineral density in inflammatory bowel disease. F Intern Med 1996;239:131-7.

31 Motil KJ, Grand RJ, Davis-Kraft L, Ferlic LL, Smith EO. Growth failure in children with inflammatory bowel Growth failure in children with inflam

32 Kirschner BS. Growth and development in chronic inflammatory bowel disease. Acta Pediatr Scand 1990;366(suppl): 98-104.

33 Mazlam MZ, Hodgson HJF. Peripheral blood monocyte cytokine production and acute phase response in inflammatory bowel disease. Gut 1992;33:773-8.

34 Cohen-Solal ME, Graulet AM, Denne MA, Gueris J, Baylink D, Vernejoul MC. Peripheral monocyte culture supernatants of menopausal women can induce bone resorption: involvement of cytokines. F Clin Endocrinol Metab 1993;77:1648-53.
35 König A, Mühlbauer RC, Fleisch $\mathrm{H}$. Tumor necrosis factor alpha and interleukin-1 stimulate bone resorption in vivo as measured by urinary $(3 \mathrm{H})$ tetracycline excreti

36 Patel S. Current and potential future drug treatments for osteoporosis. Ann Rheum Dis 1996;55:700-14.

37 Allgrove J. Biphosphonates. Arch Dis Child 1997;76:73-5.

8 van Persijn van Meerten EL, Kroon HM, Papapoulos SE. Epi- and metaphyseal changes in children caused by administration of biophosphonates. Radiology 1992;184: 249-54.

39 Silvennoimen JA, Karttunen TJ, Niemelä SE, Manelius JJ, Lehtola JK. A controlled study of bone mineral density in patients with inflammatory bowel disease. Gut 1995;37: 71-6.

40 Motley RJ, Clements D, Evans WD, et al. A four year longitudinal study of bone loss in patients with inflammatory bowel disease. Bone and Mineral 1993;23:95-104.

41 Lukert BP, Raisz LG. Glucocorticoid-induced osteoporosis: pathogenesis and management. Ann Intern Med 1990;112: pathogen

42 Kirschner BS, Sutton MM. Somatomedin-C levels in growth-impaired children and adolescents with chronic inflammatory bowel disease. Gastroenterology 1986;91: $830-6$

43 Thomas AG, Holly JMP, Taylor F, Miller V. Insulin-like growth factor-I, insulin-like growth factor binding protein-I, and insulin in childhood Crohn's disease. Gut 1993;34:944-7.

44 Solliman AT, Hassan AEHI, Aref MK, Hintz RL, Rosenfeld RG, Rogol AD. Serum insulin-like growth factors in children with protein-energy malnutrition before and after nutritional rehabilitation. Pediatr Res 1986;20:1122-30.

45 Harries AD, Brown R, Heatley RV, Williams LA, Woodhead S, Rhodes J. Vitamin D status in Crohn's disease: association with nutrition and disease activity. Gut 1985;26:1197-203.

46 Sambrook P, Birmingham J, Kelly P, et al. Prevention of corticosteroid osteoporosis. A comparison of calcium, calciticosteroid osteoporosis. A comparison of calcium, calci-
triol and calcitonin. N Engl f Med 1993;328:1747-52.

47 Finkelstein JS, Neer RM, Biller BMK, Crawford JD, Klibanski A. Osteopenia in men with a history of delayed puberty. N Engl f Med 1992;326:600-4.

TR, Duthie CM, Goran MI. Crosscalibration of fat and lean measurements by dual energy $\mathrm{x}$-ray absorptiometry to pig carcass in the paediatric weight range. Am $\mathcal{F}$ Clin Nutr 1996;63:293-8.

49 Svendsen OL, Haarbo J, Hassager C, Christiansen C. Accuracy of measurements of body composition by dual energy x-ray absorptiometry in vivo. Am f Clin Nutr 1993;57: $605-8$. 